\title{
Modelling of Deterioration Effects on Concrete Structures
}

\author{
B. Teplý
}

In order to predict the service life of concrete structures models for deterioration effects are needed. This paper has the form of a survey, listing and describing such analytical models, namely carbonation of concrete, ingress of chlorides, corrosion of reinforcing steel and prestressing tendons. The probabilistic approach is applied.

Keywords: concrete structures, service life, reinforcement, tendons, carbonation, corrosion, chloride ingress.

\section{Introduction}

There is increasing economic pressure for both newly-built and existing facilities to be kept in-service for a longer period of time. This requirement is enhanced by environmental awareness. To cope with such tasks, mathematical models can be made for the performances of a building or structure, including the process of ageing (deteriorating). Generally two classes of problems may be distinguished in this context:

(i) Prediction of service-life for structures during the design process. This becomes a necessity in the context of the new "Performance-based design" rules, which are a trend in forthcoming engineering work - see e.g. [1];

(ii) Assessment of existing structures, i.e., estimating residual service life.

To estimate future safety and performance one has to consider not only the real material, loading and technological characteristics but also possible deterioration (e.g., by corrosion), physical damage (environmental loadings, impacts), maintenance and possible repair works. In principal, these effects and their governing inputs are highly uncertain, so the adoption of a probabilistic approach is unavoidable.

Concrete structures - with mild steel or prestressed reinforcement - undergo a process of ageing due to environmental and loading agents (chemical and mechanical/physical processes) during their service. Experimental investigation is a basic procedure; however, in many situations - especially concerning more complex structural members or structures it is not feasible. The solution is to model such situations analytically. The aim of this paper is to describe some existing models of various kinds of material deterioration and to discuss their probabilistic form.

\section{Service life}

First let us briefly define the service life (or structural life-time) of a structure. According to [2] service life in general is ... the period of time after installation during which all the conditions of the structure (structural part) meet or exceed the performance requirements ... . It should be stressed that the basic requirement is structural safety. Much research has been devoted to methods and applications for service life - see, e.g., [3], [4].

Frequently the limit state concept is utilized, comprising a function for the influence of the load $S$ and a function for the load bearing capacity $R$ (or the structural resistance function). Then the following inequality should be satisfied:
$Z=R-S=R\left(X_{1}, X_{2}, \ldots, X_{n}\right)-S\left(Y_{1}, Y_{2}, \ldots, Y_{m}\right) \geq 0$ where:

$Z \quad$ - safety margin (or limit state function)

$X_{i} \quad$ - basic variable $(i=1, \ldots, n)$ of the loading function

$Y_{j} \quad$ - basic variable of the resistance function $(j=1, \ldots, m)$.

Note that the same variable may be included in both the sets $X$ and $Y$ (e.g., Young's modulus in the case of a redundant structure). For the limit state of an ageing structure, time $t$ is also included among the basic variables.

Due to the uncertainties of the parameters involved a non-deterministic analysis - i.e., a probabilistic analysis should be adopted. Then $X_{i}$ and $Y_{j}$ are either considered to be random variables or may be represented as random fields (the actual value of the parameter is subjected to scatter). A probabilistic representation of service life is depicted in Fig. 1 (extracted from [5]).

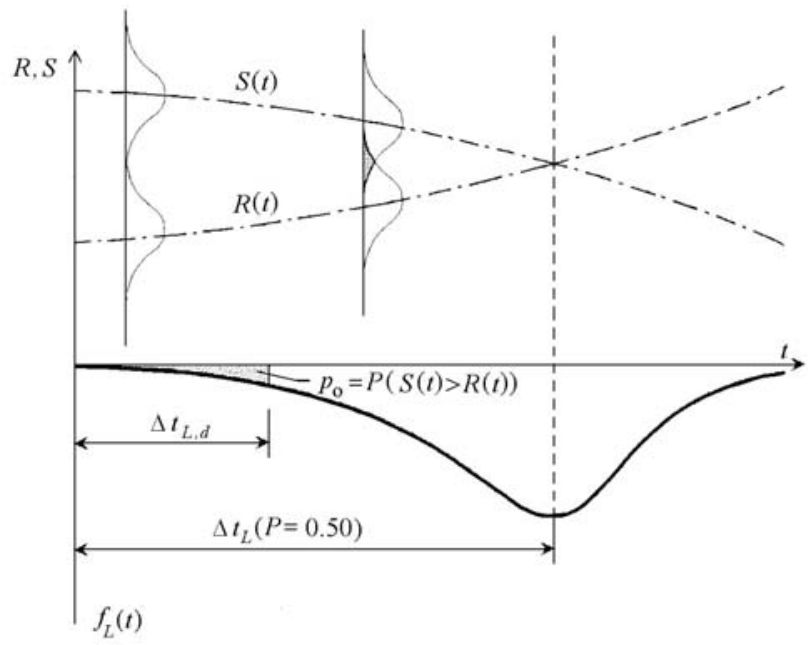

Fig. 1: Probabilistic representation of structural service life

Alternatively, the service life of reinforced concrete structures may be assessed by distinguishing two periods. First, the initiation period, during which the gradual depassivation of the reinforcing bars (due to $\mathrm{CO}_{2}$ or other effects) is in progress. Second, the propagation period, during which corrosion of the reinforcement takes place, and consequently, the failure probability is increased for both the load and serviceability limit states. This is illustrated in Fig. 2. The structural life prediction can be reached by modelling such effects. 


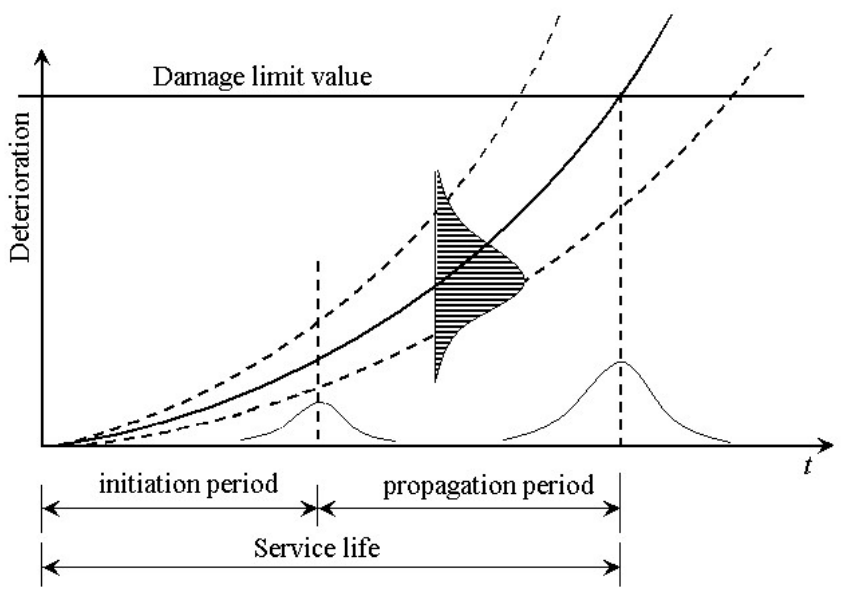

Fig. 2: Two periods of structural service life

As mentioned above the parameters in the model are in principle stochastic in nature; the actual value of the parameter is subjected to scatter. This implies that the probability can be described by, e.g., probability density functions for all parameters. Therefore it is necessary to model the uncertainties and add them to the mathematical performance model or the probabilistic service life design.

\section{Analytical models}

\section{Carbonation of concrete}

Carbonation is a chemical process in concrete driven by ambient $\mathrm{CO}_{2}$ penetrating from the surface and decreasing $\mathrm{Ph}$ up to a value approximately equal to 9 . When the carbonation depth $x_{c}$ equals the cover $c$ the steel is depassivated and corrosion may start (see also the initiation time explained above).

\section{- Papadakis et al}

The model of time-dependent carbonation depth $x_{c}$ of OPC concrete developed by Papadakis et al [6] is an analytical model based on the mass conservation of $\mathrm{CO}_{2}, \mathrm{Ca}(\mathrm{OH})_{2}$ and CSH (hydrated calcium silicate) in any control volume of the concrete mass. The simplified carbonation depth formula for OPC concrete is expressed here as:

$$
\begin{aligned}
x_{c}= & 0.35 \rho_{c} \frac{\left(\frac{w}{c}-0.3\right)}{\left(1+\frac{\rho_{c} w}{1000 c}\right)} \mathrm{f}(R H) . \\
& \cdot \sqrt{\left(1+\frac{\rho_{c} w}{1000 c}+\frac{\rho_{c} a}{\rho_{a} c}\right) c_{C O_{2}} \frac{22.4}{44} 10^{6} t},
\end{aligned}
$$

where $x_{c}$ is the carbonation depth (mm) for time $t$ (years), $\rho_{c}, \rho_{a}$ are the mass density $\left(\mathrm{kg} / \mathrm{m}^{3}\right)$ of cement and aggregates, respectively, $w / c, a / c$ are the water/cement and aggregate/cement ratio, respectively, $R H$ is the ambient relative humidity, $c_{\mathrm{CO}_{2}}$ is the $\mathrm{CO}_{2}$ content in the atmosphere $\left(\mathrm{mg} / \mathrm{m}^{3}\right)$. Aggregate unit content $a$ is calculated using the equation:

$$
a=s+g_{4-8}+g_{8-16}
$$

where $s, g_{4-8}, g_{8-16}$ are the unit content of sand, gravel size 4-8 $\mathrm{mm}$ and gravel size $8-16 \mathrm{~mm}$, respectively. Then, the mass density of the aggregates can be expressed as:

$$
\rho_{a}=\frac{a}{\frac{s}{\rho_{s}}+\frac{g_{4-8}}{\rho_{g_{4-8}}}+\frac{g_{8-16}}{\rho_{g_{8-16}}}},
$$

where $\rho_{s}, \rho_{g_{4-8}}, \rho_{g_{8-16}}$ are the mass densities of sand, gravel size 4-8 $\mathrm{mm}$ and gravel size $8-16 \mathrm{~mm}$, respectively.

In the original formulation the model does not provide satisfactory results for high values of $R H$. This has been overcome by implementing the step-wise linear relationship $\mathrm{f}(R H)$ extracted from the experiments reported by Matoušek [7], see also [8].

A total of 11 variables are involved in this model, and in some cases not all appropriate pieces of information are available. Therefore, a simpler model may be useful:

- Bob and Affana [9]

$$
x_{c}=150 \frac{C k d}{f_{c}} \sqrt{t}
$$

where $x_{c}$ is the average depth of carbonation $(\mathrm{mm}), f_{c}$ is the concrete compressive strength $(\mathrm{MPa}), t$ is the time of $\mathrm{CO}_{2}$ (years), $C$ is the coefficient of cement type, $k$ introduces the influence of humidity (environmental conditions), and $d$ is the coefficient for $\mathrm{CO}_{2}$ content.

Both the models were probabilised and compared see [10]. There are some other carbonation models - see a review [11].

\section{Chloride ingress}

Chloride ions diffuse through the protective concrete cover. After reaching the critical threshold of chloride concentration, the protective passive film around the reinforcement is dissoluted and the corrosion of the reinforcement may be initiated.

The model of chloride diffusion-adsorption in concrete by Papadakis et al. [12] can be used. This model allows us to predict the chloride concentration in the solid and liquid (aq) phases of concrete as a function of the initial concentration $\left[\mathrm{Cl}^{-}(\mathrm{aq})\right]_{i}$, of the concentration $\left[\mathrm{Cl}^{-}(\mathrm{aq})\right]_{0}\left(\mathrm{~mol} / \mathrm{m}^{3}\right)$ on the nearest concrete surface and the distance $x(\mathrm{~mm})$ from it, and that of time $t$ (years). The assumption of the formation of a moving "chloride front", where the concentration of $\mathrm{Cl}^{-}(\mathrm{aq})$ decreases to zero, gives the following expression for the distance $x_{\mathrm{Cl}}(\mathrm{mm})$ from the surface:

$$
x_{\mathrm{Cl}}=1000 \sqrt{\frac{2 D_{e, \mathrm{Cl}^{-}}\left[\mathrm{Cl}^{-}(\mathrm{aq})\right]_{0}}{3.1536\left[\mathrm{Cl}^{-}(\text {solid })\right]_{\mathrm{sat}}} t \cdot 10^{-7}}
$$

$\left[\mathrm{Cl}^{-}(\text {solid })\right]_{\text {sat }}$ denotes the saturation concentration of $\mathrm{Cl}^{-}$in the solid $\left(\mathrm{mol} / \mathrm{m}^{3}\right)$ and $D_{e, \mathrm{Cl}^{-}}$is the effective diffusivity $\left(\mathrm{m}^{2} / \mathrm{s}\right)$ :

$$
D_{e, \mathrm{Cl}^{-}}=0.15 \frac{1+\rho_{c} \frac{w}{c}}{1+\rho_{c} \frac{w}{c}+\frac{\rho_{c}}{\rho_{a}} \cdot \frac{a}{c}}\left[\frac{\rho_{c} \frac{w}{c}-0.85}{1+\rho_{c} \frac{w}{c}}\right]^{3} D_{\mathrm{Cl}^{-}, \mathrm{H}_{2} \mathrm{O}}
$$

$D_{\mathrm{Cl}^{-}, \mathrm{H}_{2} \mathrm{O}}$ denotes the diffusion coefficient of $\mathrm{Cl}^{-}$in an "infinite solution". 
If $\left[\mathrm{Cl}^{-}(\mathrm{aq})\right]_{c r}$ indicates the diffusion coefficient of $\mathrm{Cl}^{-}$in the aqueous phase $\left(\mathrm{mol} / \mathrm{m}^{3}\right)$ required for the depassivation of steel bars (a critical value), and $c_{c}$ is the concrete cover $(\mathrm{mm})$, then time $t_{c r}$ (years) to depassivation is given by:

$$
t_{c r}=\frac{\left[\mathrm{Cl}^{-}(\text {solid })\right]_{\mathrm{sat}}\left(c_{c} / 1000\right)^{2}}{3.1536 \cdot 10^{7} \cdot 2 D_{e, \mathrm{Cl}^{-}}\left[\mathrm{Cl}^{-}(\mathrm{aq})\right]_{0}\left(1-\frac{\left[\mathrm{Cl}^{-}(\mathrm{aq})\right]_{c r}}{\left[\mathrm{Cl}^{-}(\mathrm{aq})\right]_{0}}\right)^{2}}
$$

Again, other models do exist - let us mention (without making a detailed description), e.g., the model based on Fick's second law and utilized in [13].

\section{Simultaneous effect of $\mathrm{Cl}^{-}$and $\mathrm{CO}_{2}$}

Simultaneous contamination of carbon dioxide and ingress of chloride ions is rather common in reality, but unfortunately there are few works devoted to this problem. In this context the research work [14] has to be mentioned. This experimental study investigates the effect of fly ash addition on the corrosion process in reinforced concrete exposed to carbon dioxide and chloride. It has been shown that in a strongly aggressive chloride environment (a sea coast or locations with frequent use of de-icing salts) the addition of fly ash is beneficial. Conversely, in locations with a high concentration of $\mathrm{CO}_{2}$ fly ash may accelerate the corrosion process. Reference mortar samples without fly ash were also studied, and it has been proved that the carbonation process affects the chloride profile.

To the author's best knowledge, no analytical model exists for predicting the possible synergetic effect of carbon dioxide and ingress of chlorides.

\section{Steel corrosion - mild steel}

Reinforcement corrosion is in progress during the propagation period and its rate is governed by the availability of water and oxygen on the steel surface. Due to corrosion, the effective area of steel decreases and rust products grow, causing at a certain stage longitudinal cracking and later spalling of concrete, or delamination.

\section{- Andrade et al}

Note that both the uniform (or general) type and the pitting (localized) type of corrosion should be modelled. Recently, the model used by, e.g., [15], [16] seems to be sufficient for the prediction of uniform corrosion. The formula for the time related rebar diameter decrease reads

$d(t)= \begin{cases}d_{i} & t \leq T_{i} \\ d_{i}-0.0116 i_{\text {corr }} \alpha\left(t-T_{i}\right) & T_{i}<t \leq T_{i}+\left(d_{i} / 0.0116 i_{\text {corr }} \alpha\right)(9) \\ 0 & t>T_{i}+\left(d_{i} / 0.0116 i_{\text {corr }} \alpha\right)\end{cases}$

where $d_{i}$ is the initial bar diameter $(\mathrm{mm}), T_{i}$ is the time to initiation (years) and $i_{\text {corr }}$ is the current density (normally expressed in $\mu \mathrm{A} / \mathrm{cm}^{2}$ ). Parameter $\alpha$ expresses the type of corrosion. For homogeneous corrosion $\alpha$ equals 2, however, when localised corrosion (pitting) occurs, $\alpha$ may reach values from 4 up to 8 (see [16]). In this latter case the representation of the corrosion is not accurate enough.

For localised corrosion, the following models can also be taken into consideration. The studies by Gonzalez et al [17] show that the maximum rate of corrosion penetration in the case of pitting corrosion is $4-8$ times that of general corrosion. The depth of the pit at time $t$ can be estimated by the equation

$$
p(t)=0.0116 i_{\text {corr }} R_{\text {corr }}\left(t-T_{i}\right)
$$

with $i_{\text {corr }}$ taken as $3 \mu \mathrm{A} / \mathrm{cm}^{2}$, a value indicative of a high rate of corrosion, and $R_{\text {corr }}=6$. The corrosion is assumed to be confined to discrete pits.

\section{- Val and Melchers}

Advanced modelling of localised corrosion was presented by Val and Melchers [18]. The residual section at the pits can be predicted by simplification in a hemispherical form. The net cross sectional area of a corroded rebar, $A_{r}$, at time $t$, is calculated as

$$
A_{r}(t)= \begin{cases}\pi \frac{d_{i}^{2}}{4}-A_{1}-A_{2} & p(t) \leq \frac{\sqrt{2}}{2} d_{i} \\ A_{1}-A_{2} & \frac{\sqrt{2}}{2} d_{i}<p(t) \leq d_{i} \\ 0 & p(t)>d_{i}\end{cases}
$$

where

$$
\begin{gathered}
A_{1}=\frac{1}{2}\left[\theta_{1}\left(\frac{d_{i}}{2}\right)^{2}-a_{p}\left|\frac{d_{i}}{2}-\frac{p(t)^{2}}{d_{i}}\right|\right], \\
A_{1}=\frac{1}{2}\left[\theta_{2} p(t)^{2}-a_{p} \frac{p(t)^{2}}{d_{i}}\right] \\
a_{p}=2 p(t) \sqrt{1-\left(\frac{p(t)}{d_{i}}\right)^{2}}, \\
\theta_{1}=2 \arcsin \left(\frac{a_{p}}{d_{i}}\right), \quad \theta_{2}=2 \arcsin \left(\frac{a_{p}}{2 p(t)}\right)
\end{gathered}
$$

and $p$ is the radius of the pit.

It should be noted that pitting corrosion is highly localized on individual reinforcement bars. It is unlikely that many bars could be affected; hence pitting corrosion will not significantly influence the structural capacity of a cross-section.

\section{Stress corrosion cracking (SCC)}

The tension of a prestressing wire may induce the presence of cracks and a special type of corrosion - Stress Corrosion Cracking (SCC). The brittle fracture and fatigue limit state should be considered in this case. Fracture mechanics is used to analyze such effects.

According to [19] the SCC effect can be modelled in the following way: Let $\sigma$ be the effective tension in a wire, and $a$ be the crack depth caused by corrosion. The tension at the depth of the crack is calculated as

$$
\sigma_{a}=\frac{P}{S} K(a)
$$

$P$ is the force in the wire (in N), $S$ is the cross sectional area of the wire and $K(a)$ is the stress intensity factor. Its value can be calculated with the aid of the equation of linear fracture mechanics 


$$
\frac{K}{s \sqrt{\pi a}}=\sum_{i=0, j \neq 1}^{4} \sum_{j=1}^{3} C_{i j}\left(\frac{a}{D}\right)^{i}\left(\frac{a}{b}\right)^{j}
$$

where $b$ is the width of the crack (in $\mathrm{m}$ ), $D$ is diameter of wire and $C_{i j}$ are given in [19] - table 4 . When the value of $K(a)$ reaches the critical value $K_{I S C C}$ (fracture toughness) the wire breaks suddenly.

Fig. 3 represents the dependability of time, crack depth and fracture toughness $\left(a_{0}, a_{c}\right.$ are the initial, resp. critical crack depths).

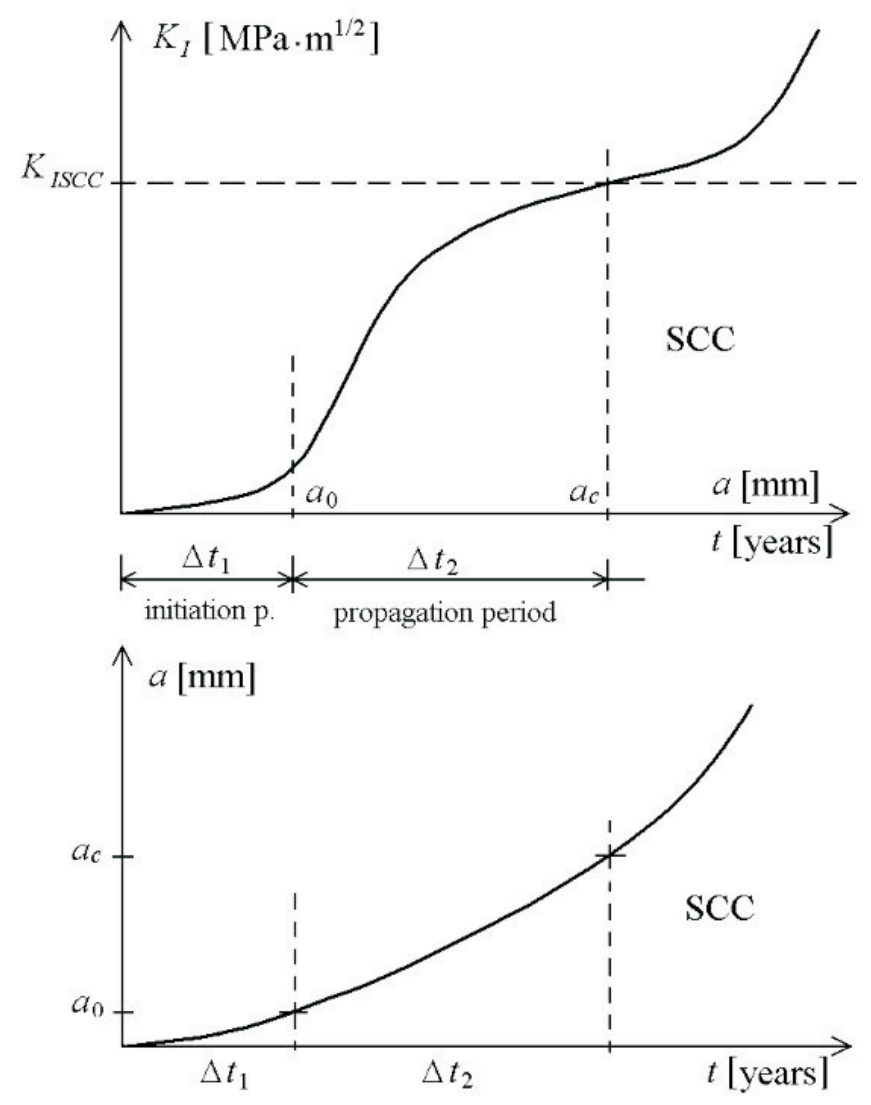

Fig. 3: Fracture toughness vs. time and crack depth

Note: In the cases of precast prestressed members or well-grouted tendons, reanchoring should be considered at a certain distance from the point of failure. This distance may be evaluated according to Building code requirements for reinforced concrete (ACI 318-89), R 12.8. The referred minimum value is 6 inches.

Pitting and SCC corrosion types develop lesser expansion activity than the general case, and therefore the chance of visual detection (cracks on the concrete surface) is often negligible.

\section{Assessment of structures - random nature}

\section{- Statistical analysis}

The basic parameters of the carbonation (or other degradation effects) computational models described above are very uncertain. Their variability may be significant and stochastic modelling is desirable. Therefore, the input variables should be considered to be random variables described by theoretical probability density functions.

Then the predicted carbonation depth $x_{c}(\mathbf{X})$ or the time to depassivation $t_{c r}(\mathbf{X})$ are the functions of random variables $\mathbf{X}=X_{1}, X_{2}, \ldots, X_{m}$. The level of the probabilisation is given by the decision which input variables will be considered as random and which as deterministic. Sensitivity analysis may serve as a tool for such decision-making.

The goal of statistical analysis is to estimate the basic statistical parameters of these degradation effects, e.g., their mean values and variances. This can be done by Monte Carlo simulation, i.e., by repetitive calculations of the carbonation/chloride attack formula. A special type of numerical simulation, Latin Hypercube Sampling (LHS), makes it possible to use a small number of simulations. For an application, see, e.g., [4].

\section{- Probability analysis}

Concrete and reinforcing steel materials deteriorate in time, and consequently, e.g., the ultimate bending moment or other resistance variables decrease. The goal is to quantify the influence of structural deterioration on the reliability of the structure in question. The failure probability is defined as:

$$
p_{f}=P(g(\mathbf{X}, t) \leq 0)
$$

and can be evaluated at several time points $t_{i}(i=1,2, \ldots, n)$. $g($.$) is the appropriate limit function. The increase of failure$ probability in time can be estimated, e.g., by advanced simulation techniques, such as importance sampling.

\section{- Sensitivity analysis}

Sensitivity analysis is usually an additional output of reliability analysis. There are many approaches to sensitivity analysis - see, e.g., [20]. The goal of this analysis is to answer the question "how is the variability of the safety margin influenced by the individual random variables". And since the variability of the safety margin directly influences the failure probability, this sensitivity measure can be understood as a measure of the influence on the theoretical failure probability. An application of sensitivity analysis of a deteriorating structure may be found, e.g., in [4].

\section{- Structural service life}

A definition of service life is depicted in Fig. 1 (as the intersection of the loading action curve and the structural resistance function - both random!).

\section{- Bayesian Updating}

The results of statistical simulation are based on statistical data, which may be more or less accurate, obtained by measurement, taken from literature or based on an engineering judgment. This data should be available from design documentation, while some may be gained by engineering judgment or from specialized databases (if available!). A computational model for the prediction of, e.g., carbonation depth cannot be considered as the most accurate source, considering all factors involved. Such results are, therefore, "a prior information" related to the available data and the theoretical model. The prior prediction for both short-term and long-term effects is obtained by this simulation. 
Bayesian statistical prediction combined with LHS is described in [21]; application to improved (a posterior) prediction of the carbonation time profile is shown in [8]. The objective was to use the measurement to improve or update the long-term values of carbonation depth.

Note that if the data obtained by measurement is too remote from the prior results, then Bayesian updating fails [21]

\section{Acknowledgements}

This study has been supported by Grant Agency of Czech Republic project No. 103/02/1030.

\section{References}

[1] Smith, I.: Increasing Knowledge of Structural Performance. Structural Engineering International, Vol. 11, No. 3, 2001, p. 191-195.

[2] ISO 15686-2: Buildings and construction assets - Service life planning. International standard.

[3] Sarja, A.: Towards Practical Durability Design of Concrete Structures. In: Durability of Building Materials and Components Vol. 2. London: E\&F Spon, 1999, p. 1237-1247.

[4] Teplý, B. et al: Deterioration of Reinforced Concrete: Probabilistic and Sensitivity Analyses. Acta Polytechnica, 1999, Vol. 39, No. 2, p. 7-23.

[5] Siemes, T., Rostam, S.: Durable Safety and Serviceability - a Performance Based Design Format. Delft, Report of IABSE Colloquium 1996, p. 41-50.

[6] Papadakis, V. G., Fardis, M. N., Vayenas, C. G.: Effect of Composition, Environmental Factors and Cement-lime Mortar Coating on Concrete Carbonation. Materials and Structures, 1992, Vol. 25, No. 149, p. 293-304.

[7] Matoušek, M.: Effects of some Environmental Factors on Structures. Ph.D. thesis, Technical University of Brno, Czech Republic (in Czech), 1977.

[8] Novák, D., Keršner, Z., Teplý, B.: Prediction of Structure Deterioration Based on the Bayesian Updating. Natural-Draught Cooling Towers, Rotterdam, Balkema 1996, p. $417-421$.

[9] Bob, C., Afana, E.: On-site assessment of concrete carbonation. Proceedings of the international conference "Failure of concrete structures, Štrbské Pleso, Slovak Republic, 1993, p. 84-87.

[10] Keršner, Z., Teplý, B., Novák, D.: Uncertainty in Service Life Prediction Based on Carbonation of Concrete. Durability of Building Materials and Components 7, London: E \& FN SPON 1996, Vol. 1, p. 13-20.
[11] Parrot, L. J.: A review of carbonation in reinforced concrete. British Cement Association Report C/1,0987, London 1987.

[12] Papadakis et al: Mathematical Modelling of Chloride Effect on Concrete Durability and Protection Measures. Concrete in the Service of Mankind, London: E \& F. SPON, 1996, p. 165-174.

[13] Karimi, A. R., Ramachandran, R.: Probabilistic estimation of corrosion in bridges due to chlorination. Rotterdam: Balkema 2000, p. 681-688.

[14] Montemor, M. F. et al: Corrosion behaviour of rebars in fly ash mortar exposed to carbon dioxide and chlorides. Cement \& Concrete Composites, 2002, Vol. 24, p. 45-53.

[15] Andrade, C., Sarria, J., Alonso, C.: Corrosion Rate Field Monitoring of Post - Tensioned Tendons in Contact with Chlorides. Durability of Building Materials and Components 7, London: E \& FN SPON 1996, Vol. 2, p. 959-967.

[16] Rodriguez, J., Ortega, L. M., Casal, J., Diez, J. M.: Corrosion of Reinforcement and Service Life of Concrete Structures. Ibid, Vol. 1, p. 117-126.

[17] Gonzales, J. A. et al: Comparison of rates of general corrosion and maximum pitting penetration on concrete embedded steel reinforcement. Cement and Concrete Research, Vol. 25, No. 2, 1995, p. 257-264.

[18] Val, D., Melchers, R. E.: Reliability analysis of deteriorating reinforced concrete frame structures. Structural Safety and Reliability, Rotterdam: Balkema 1998, p. 105-112.

[19] Izquierdo, D., Andrade, C., Tanner, P.: Reliability Analysis of Corrosion in Post-tensional Tendons: Case Study. Proceedings of the international conference "Safety, Risk, Reliability - Trend in Engineering”, Malta 2001, p. 1001-1006.

[20] Novák, D., Teplý, B., Shiraishi, N.: Sensitivity Analysis of Structures: A Review. International conference CIVIL COMP '93, Edinburgh, Scotland, 1993, p. 201-207.

[21] Bažant, Z. P., Chern, J. C.: Bayesian Statistical Prediction of Concrete Creep and Shrinkage. ACI Journal, Vol. 81, No. 6, 1984, p. 319-330.

Prof. Ing. Břetislav Teplý, CSc.

tel.: +420541 147642

fax: +420541 147667

e-mail: teply.b@fce.vutbr.cz

Brno University of Technology

Faculty of Civil Engineering

Žižkova 17

66237 Brno 